\title{
O REGIME DE ACUMULAÇÃO FINANCEIRA E A SITUAÇÃO DO BRASIL: UMA ANÁLISE PARA O PERÍODO PÓS-ESTABILIZAÇÃO MONETÁRIA
}

\author{
Jamile Ulisses Pereira \\ Mestranda em Desenvolvimento Econômico, \\ Universidade Federal do Rio Grande do Sul(UFRGS) \\ Rio Grande do Sul, RS, Brasil. \\ jamile ulisses@hotmail.com
}

\begin{abstract}
Resumo - Este artigo tem como objetivo analisar o regime de acumulação do Brasil no período após o Plano Real, compreendendo que este se realiza como um marco institucional de um novo padrão de ganhos, voltado para as elevadas rendas de juros. A literatura utilizada nos fornece os conceitos de dominância financeira ou ainda de um regime de acumulação do tipo finance-led, tentando estabelecer os vínculos estruturais e conjunturais entre a acumulação financeira e a produtiva. Essa provisão se faz necessária na busca de uma resposta a um questionamento comum em relação ao regime de crescimento nacional, que é o fato de que apesar da estabilidade de preços e das condições favoráveis para o comércio exterior, a performance macroeconômica brasileira tem permanecido muito abaixo do que se espera para uma economia ainda em desenvolvimento.
\end{abstract}

Palavras-chave: Financeirização, Regime de Acumulação, Regulação.

\section{THE FINANCIAL ACCUMULATION SCHEME AND THE SITUATION OF BRAZIL: AN ANALYSIS FOR THE POST-STABILIZATION PERIOD}

\begin{abstract}
This paper aims to analyze accumulation regime of Brazil in the period after Plano Real, understanding that this an institutional framework of a new pattern of gains, focused on high interest income. The literature used provides us with the concepts of financial dominance or a financial-led accumulation regime, trying to establish the structural and conjunctural links between financial and productive accumulation. This provision is necessary in the search for a response to a common question regarding the national growth regime, which is the fact that despite the stability of prices and favorable conditions for foreign trade, the Brazilian macroeconomic performance has remained much below than expected for a developing economy.
\end{abstract}

Key words: Financialization; Accumulation Regime; Regulation.

\section{INTRODUÇÃOO}

As condições do desenvolvimento econômico sofreram grandes mudanças com as transformações recentes na forma de organização do capitalismo global. O crescimento vertiginoso das transações financeiras foi um dos fatos mais significativos da década de 1980, representando o movimento de mundialização da economia (CHESNAIS, 1998). Fornecer elementos analíticos que permitam estabelecer as ligações entre a mundialização financeira e os outros elementos constitutivos essenciais ao sistema econômico tornou-se, portanto, um objeto de pesquisa comum, dada a acepção de que são significativos os impactos econômicos e sociais engendrados por esse tipo de acumulação, sobretudo no que se refere aos seus efeitos na estrutura produtiva, impactando diretamente na geração de emprego e renda, e na estabilidade do crescimento econômico. 
Claramente, os movimentos de valorização desse tipo não são recentes, porém o protagonismo que a propriedade e o rentismo assumiram é inédito, permitindo qualificar a tese da financeirização do capitalismo. Esse processo foi possibilitado pelo maior acesso das famílias ao mercado financeiro, a elevação significativa dos intermediários financeiros e uma influência desse novo cenário nas ações das firmas, dos grupos familiares e das formas de condução de política macroeconômica e sociais pelos Estados nacionais (ANDRADE \& FERES, 2018).

Dessa forma, diferentes abordagens sobre o processo de financeirização da economia são desenvolvidas. Van der Zwan (2014) identifica pelo menos três delas em voga na academia: i) o fenômeno visto como um novo regime de acumulação; ii) o processo tomado a partir de seus efeitos sobre as corporações; iii) como fator gerador de transformações no dia a dia da sociedade, obtendo um foco também cultural. A primeira delas, possuindo entre seus membros seguidores de diversas escolas de pensamento, mas principalmente da Escola Regulacionista Francesa, obterá nossa atenção.

Uma das problemáticas regulacionistas são a identificação e a transformação das condições que asseguram a coesão e a estabilidade de um regime de acumulação. Com o movimento de financeirização que ocorreu a partir da década de 1980, vieram à tona novas questões devido às dificuldades das economias nacionais em encontrar regimes de acumulação estáveis. Baseando-se nas características que marcam o capitalismo desse período, François Chesnais, em diferentes trabalhos a partir da década de 1990, passa a defender a tese de que o capitalismo vive sob um regime de acumulação comdominância da valorização financeira, tendo constituído um modo de regulação adequado a esse tipo de acumulação. A partir dessa premissa, tentaremos caracterizar, de maneira geral, o regime de acumulação financeirizado para a economia brasileira do período pós 1994, seu estatuto teórico e suas consequências macroeconômicas.

Os vínculos estruturais e conjunturais entre a acumulação de base rentista e a acumulação de capital fixo produtivo são fatores fundamentais nos estudos a respeito do desenvolvimento econômico atual, uma vez que se compreende que, nos países em que o processo de financeirização mais avançou, tenha ocorrido queda da participação do capital fixo produtivo no estoque de capital total, baixas taxas de crescimento e elevação do desemprego estrutural (BOYER, 2000). Nessas condições, taxas de expansão prolongadas ficam obstaculizadas, sendo significativas as transformações estruturais do período e que elevam as finanças a uma posição dominante no processo de revalorização docapital.

\section{A REGULAÇÃO $\quad$ COMO PRINCÍPIO TEÓRICO - CONTEXTUALIZAÇÃO}

A vertente teórica regulacionista busca elaborar um instrumental capaz de traduzir as condições que permitem a reprodução de um sistema socioeconômico, coerente e com algum grau 
de regularidade, apesar e a partir mesmo dos conflitos que arquiteta. Ou como definido por Bruno (2005), a noção de regulação é mobilizada para transmitir, no plano das macroanálises, as condições endógenas que permitem a reprodução do sistema socioeconômico, através da gestão de novas formas ou estruturas organizativas, caracterizadas por sua historicidade, no qual em cada momento histórico determinado o processo de acumulação capitalista assume uma forma específica.

Para tanto, são utilizadas duas categorias principais: o regime de acumulação, que descreve as evoluções conjuntas das condições de produção com as condições que respondem pelo uso social do produto, e o modo de regulação, que vem a ser o conjunto dos procedimentos e comportamentos individuais ou coletivos capazes de reproduzir as relações fundamentais ao processo de acumulação, guiar o regime de acumulação vigente e assegurar a compatibilidade dos princípios de ajustamento do sistema (PAULANI, 2009). Quando articulados, esse binômio determina a forma específica de acumulação de capital em cada momento histórico.

Esse projeto teórico foi concebido em um contexto socioeconômico de mudançasnasrelaçõesdeproduçãoedeemergênciadaslutassociaisfrancesas, ausentes das teses usuais da teoria econômica. O conjunto de práticas de controle de trabalho, tecnologias, hábitos de consumo e configurações do poder político econômico conhecido como fordista, sob o qual se havia alcançado taxas relativamente elevadas e estáveis de crescimento econômico, já apresentava manifestações da crise estrutural que levariam à transformação desse sistema em outro com características mais flexíveis dos processos e mercados de trabalho, dos produtos e dos padrões de consumo, convivendo com níveis mais elevados de desemprego estrutural e com a redução do poder de barganha dos sindicatos de trabalhadores (HARVEY, 1989).

De acordo com Coutinho (1990), a primeira geração de trabalhos regulacionistas procurou expressar essa nova realidade, elaborando uma crítica à teoria do equilíbrio neoclássica ao mesmo tempo em que pretendia renovar a crítica da economia política. Para os autores regulacionistas, o ponto de partida seria o impacto das mudanças de um conjunto de relações sociais sobre as condições de regularidade da acumulação. $\mathrm{O}$ grau de maturidade dessas relações engendraria diferentes configurações sociais que condicionam as regularidades na acumulação.

Tendo como ponto de partida a hipótese do papel central da acumulação na explicação da dinâmica das economias capitalistas, a obra de Michel Aglietta, Régulation et crises du capitalisme, publicada na França em 1976, é considerada a primeira sistematização dessa abordagem. A maneira como o autor desenvolve seus argumentos demonstra que um dos objetivos da investigação regulacionista é a análise sistêmica da economia, construindo leis gerais que estejam determinadas socialmente e cujas condições históricas de validez se identifiquem claramente. Para ele, o objeto da teoria da regulação seriam as leis que regem a produção e a distribuição em coletividades organizadas, tendo como essência os seguintes 
questionamentos: quais são as forças que transformam o sistema social e asseguram sua coesão no longo prazo? Podem evoluir as condições e modalidades dessa coesão? Através de que condições e segundo quais processos se produzem mudanças significativas nas relações de produção? É possível identificar as etapas do desenvolvimento capitalista? Esse método de análise serve para interpretar as crises estruturais que afrontam o modo de produção? Ele permite elaborar hipóteses sobre o futuro da luta declasses?

Em Boyer (2009), podemos encontrar três hipóteses fundadoras da teoria regulacionista, são elas: o processo de acumulação de capital é determinante na dinâmica macroeconômica; esse mesmo processo não é autoequilibrado por fenômenos puramente mercantis e concorrenciais e por fim, que a sinstituições e as formas estruturais são determinantes para direcionar o processo de acumulação. Dessa forma, o conceito de regulação permite construir as bases para uma macroeconomia histórica e institucionalista, revelando os movimentos de conservação e de rupturas presentes, uma vez que ao longo da história, o modo de produção capitalista desenvolve-se através de diferentes modos de regulação e de regimes de acumulação.

\section{O REGIME DE ACUMULAÇÃO COM DOMINÂNCIAFINANCEIRA}

A partir da década de 1980 a esfera financeira coloca-se como um dos pontos centrais da análise do processo de acumulação. Segundo Epstein (2005), nesse período a economia mundial mudou sua configuração através da diminuição do papel dos governos frente ao poder de mercado; o crescimento das transações comerciais entre os países, assim como das transações financeiras domésticas e internacionais. Essas alterações foram caracterizadas pela volta da perspectiva liberal frente à keynesiana, a globalização e a financeirização, definida pelo autor como o "crescente papel das motivações, mercados, atores e instituições financeiras nas operações econômicas”. Já Krippner (2005) define o fenômeno como "um padrão de acumulação no qual os lucros advêm primariamente através dos canais financeiros ao invés do comércio e da produção industrial". Os canais financeiros seriam quaisquer atividades de provisão e de transferência de capital líquido na expectativa de ganhos futuros, sejam eles juros, dividendos ou ainda outras formas de capital.

Para Chesnais (1998), a esfera financeira representa a ponta de lança do movimento da mundialização da economia, envolvendo os montantes mais elevados de capital, com maior mobilidade e onde os interesses privados se fortaleceram em relação ao Estado. A mundialização financeira teria nascido de um processo de interação entre o movimento de fortalecimento do capital privado, tanto industrial como bancário, e o crescente impasse das políticas governamentais, fazendo surgir um regime alternativo apto a sustentar o consumo frente à estagnação dos salários reais. Dessa forma, seu funcionamento é ordenado, em grande medida, pelas operações e opções do capital financeiro, mais concentrado e centralizado do que 
em qualquer período anterior. As características do investimento produtivo, do ponto de vista do ritmo, do montante e da orientação setorial, levam o autor a formular a hipótese de que, pela primeira vez na história do capitalismo, no centro do sistema, a acumulação de capital não mais se coloca claramente sob o signo da reprodução ampliada.

No debate acadêmico, o termo foi introduzido como uma perspectiva crítica à concepção do papel dos mercados financeiros sobre a hipótese de eficiência alocativa, sendo os mercados financeiros considerados um subconjunto do sistema econômico que distribui poder e afeta a dinâmica da produção e da distribuição de renda (BRUNO, 2008). Dentro dessa perspectiva crítica, a análise regulacionista costuma compreender o processo de financeirização a partir do que se chama de "crise do modo de regulação fordista", uma vez que a massa de capitais procurando valorizar-se de forma financeira, só pode ser analisada levando em conta as crescentes dificuldades de valorização do capital investido na produção. Logo, a financeirização pode ser vista como um regime de acumulação substituto do regime de acumulação tipicamente fordista.

A prevalência da valorização financeira é mais qualitativa do que quantitativa, apesar do crescimento vertiginoso desse tipo de riqueza. As próprias instituições que se especializaram na acumulação pela via da finança tornaram-se também proprietárias dos grupos empresariais mais importantes em nível global e impuseram à própria acumulação de capital produtivo uma dinâmica orientada pela maximização do valor acionário (CHESNAIS, 2005). No que tange à gestão corporativa, a lógica financeira alojada na esfera produtiva explica inúmeras mudanças ocorridas aí, tais como as expectativas mais de curto prazo, o maior destino de lucros a pagamento de dividendos e recompra de ações e os processos de terceirização. No que tange à distribuição de renda, tais análises revelam duas grandes propensões: diminuição da participação da renda do trabalho na renda nacional e aumento da dispersão da distribuição salarial.

Lavinas, Araújo \& Bruno (2017) trazem ainda outras características de um regime de acumulação financeirizado não citados nesse trabalho, tais como: booms de consumo das famílias com base no crédito, em particular por parte daquelas que não costumavam ser bancarizadas; rápida e acentuada elevação do grau de endividamento das famílias, comprometendo parcela crescente e alta da renda disponível; e por fim, a substituição da provisão pública, principalmente nos sistemas de saúde, educação e de previdência social, que passam a serem nichos de mercado com potencial de expansão e revalorização. Como evidenciado no relatório da UNCTAD (2016), a maior parte das abordagens heterodoxas destaca que o avanço da financeirização impactou na demanda por conta das alterações da estrutura de distribuição da renda. Na esfera microeconômica, no qual os ganhos de produtividade não são reinvestidos na corporação, mas sim distribuídos aos acionistas ou usados para a compra de produtos financeiros, há uma perda da capacidade de investimento de longo prazo. 
Ficam claros, com isso, alguns dos efeitos prejudiciais desse formato de acumulação. Epstein (2005) apresenta também a ideia de que as finanças se beneficiam dos mesmos processos que criam crises econômicas, comprometendo assim, a estabilidade do crescimento econômico. $\mathrm{O}$ modo de regulação de um regime de acumulação sob dominância financeira passa a se desenvolver com base em uma sériede medidas que tem como intuito restringir o acúmulo de desequilíbrios e vulnerabilidades que são parte integrante dessa dinâmica. Esse aspecto sugere uma estrutura de políticas amplas, nas quais as políticas prudenciais, monetárias e fiscaisdevem complementar-se mutuamente, mitigando os resultados dos desequilíbrios financeiros em busca de uma economia mais resiliente, definida, de forma primária, como uma economia com capacidade de se recuperar rapidamente de choques adversos. Em nota do BIS (Bank for International Settlements), denominada Economic resilience: a financial perspective, são apresentadas algumas medidas para um quadro de estabilidade macroeconômica, respondendo ao ciclo financeiro. Elementos dessearcabouço incluem ferramentas de diagnóstico e de monitoramento, considerando, em particular, os estoques acumulados de dívida, a alavancagem, as defasagens de vencimentos e a moeda dos ativos e passivos. Os desafios na identificação de pontos de inflexão no ciclo financeiro sugerem a consideração de uma série de indicadores, que serviriam então, como ponto de partida para análises mais profundas e para asdiscussões de políticas econômicas.

A despeito disso, Chesnais (2005) argumenta que a mundialização financeira é marcada por uma carência de instâncias de supervisão e de controle, fazendo com que a discussão em tomo da teoria das crises continue se constituindo em um campo teórico dos mais férteis. Para uma análise com base na teoria da regulação, insistir sobre as condições de uma acumulação viável leva a um interesse simultâneo pelos fatores de desestabilização presentes. Sendo a crise e a regulação dois momentos que se sucedem e com a instabilidade já descrita por uma regulação dominada pela finança, é importante examinar a viabilidade e a generalidade de tal regime.

\section{FINANCE-LED GROWTH REGIMENO BRASIL:ESTATUTO TEÓRICO E CONSEQUÊNCIAS MACROECONÔMICAS}

Os estudos referentes à financeirização enquanto estágio atual de desenvolvimento do capitalismo acabaram privilegiando os países de economia central,porém o Brasil foi personagem desse processo desde o seu início. Autores como Paulani (2012) e Serrano (2004) apontam que já na década de 1950 os projetos desenvolvimentistas na periferia capitalista foram beneficiados pela maior integração comercial e desenvolvimento do sistema financeiro e monetário, em um período de rápido crescimento econômico e dentro do contexto geopolítico da Guerra Fria. Com isso, a industrialização da periferia deste período teria servido para dar sobrevida ao processo de acumulação produtiva, buscando novos locus de investimento em razão das crescentes dificuldades de valorização observadas no centro do sistema ao mesmo

\begin{tabular}{llllll}
\hline REVISTA ECONOMIA POLÍTICA DO DESENVOLVIMENTO & Maceió - AL & V.5 N.7. & JUNHO/2018 & P.68-79 & Página-73
\end{tabular}


tempo em que preparava as condições para a dominância financeira que adivinha, respondendo os anseios de uma esfera financeira em vias de expansão e ganhos de autonomia.

Enquanto Paulani (2009) aponta que o Brasil se insere no contexto da financeirização inicialmente como demanda por crédito, mas apenas a partir da segunda metade dos anos 1990 o país teria se tornado uma potência financeira emergente, tendo, para tanto, realizado diversas reformas estruturais necessárias; já na década de 1980 Braga (1985) discorria sobre o processo de financeirização precoce da economia brasileira, concluindo que esse regime inibia a imobilização de capital no setor produtivo e impunha-se como um entrave estrutural ao crescimento econômico. Para o autor, a financeirização é definida como uma norma sistêmica de riqueza que produz uma dinâmica estrutural articulada segundo os princípios da lógica financeira. Ela se caracteriza em âmbito global e condiciona as estratégias de todos os agentes privados relevantes assim como também condiciona as operações de financiamento e de despesas públicas.

Corroborando com essa acepção, Lavinas, Araújo \& Bruno (2017) partem do pressuposto de que já nos anos 70 começa a ser gestado um processo de financeirização no país. Para os autores, após o "milagre brasileiro" (1967-1973), os mecanismos institucionais de correção monetária se difundem, fazendo surgir a moeda indexada. As crises fiscais e da dívida externa da década de 1980 vão possibilitar uma expansão financeira e concentração bancária sem precedentes, tendo como ponto de partida o processo de inflação inercial. A economia brasileira esteve sujeita, assim, a um processo de financeirização baseado nos ganhos inflacionários derivados dos mecanismos de correção monetária e de indexação generalizada do período. Ainda segundo os autores, consolidando-se como setor hegemônico diante das demais atividades econômicas e do Estado nacional, o setor bancário-financeiro brasileiro pautou as transformaçõesinstitucionais que levaram à liberalização comercial e financeira dos anos 1990. Essas alterações deslocaram o eixo da acumulação dos ganhos inflacionários para a elevada renda de juros, dessa forma os canais de apropriação do excedente econômico pela finança brasileira elevam a acumulação patrimonial a um novo patamar.

Em consequência, um novo regime de acumulação surge. As evidências obtidas através da revisão de literatura realizada corroboram a hipótese de que esse regime de crescimento aproxima-se do tipo finance-dominated accumulation regime ou finance-led growth regime. $\mathrm{O}$ sentido do novo regime de acumulação se classificar dessa forma é justificado pelo fato da rentabilidade financeira comandar as decisões de alocação de capital. As finanças não estão, portanto, a serviço da acumulação produtiva e do crescimento econômico, mas se estruturam, prioritariamente, para a acumulação financeira epatrimonial.

Entretanto, para que esse regime se realize e se reproduza, é necessário que algumas forças institucionais ajam como forças coercitivas ou incentivadoras.Esse conjunto de formas é 
chamado de modo de regulação, correspondendo às especificidades de certa configuração das estruturas institucionais e organizacionais que permitem essa reprodução. O processo social pelo qual as formas institucionais tem origem e a maneira como atuam sobre a atividade econômica podem ser descritos em duas etapas, segundo Faria (2001). Primeiramente, nos níveis jurídico e político, onde se definem as regras e as convenções. Num segundo momento, no nível econômico propriamente dito, onde a interação dos agentes em torno dessas regras irá resultar numa certa distribuição da renda e da riqueza. Para uma economia organizada em bases capitalistas, cinco formas institucionais são consideradas fundamentais: a) a relação salarial; b) o regime monetário-financeiro; c) a forma da concorrência; d) as relações entre Estado e economia e e) a forma de inserçãointernacional.

A constituição de um determinado modo de regulação estabelece certa hierarquia entre as formas institucionais. Alguns trabalhos para o Brasil discutem que o período após década de 1990, caracterizado pelo aprofundamento dos processos de abertura comercial e financeira, é marcado pela dominância dessa forma institucional sobre as outras. Boyer (2000) encontra essa dominância da forma de inserção internacional para os para os países desenvolvidos do período pós mundialização financeira, explicitando algumas consequências sobre as outras formas institucionais, aos quais listaremos a seguir devido às possibilidades de efeitos similares para oBrasil:-Na forma da concorrência: desestabilização da concorrência nacional devido os processos de abertura comercial e financeira; alterações no modo de governança das empresas, com alterações significativas na relação trabalhista, na gestão do processo de trabalho ou ainda na organização do processo produtivo; os processos das firmas passam a ser adequados às necessidades de giro rápido, afetando diretamente a repartição dasrendas;

- No regime monetário-financeiro: passa a ser submisso aos mercados financeiros internacionais; o controle da inflação passa ao primeiro plano da políticamonetária;

- Na relação entre o Estado e economia: redução do papel produtivo e planejador do Estado; déficits públicos passam a ser interpretados como sinais de mágestão;

- Na relação salarial: trabalho visto apenas como variável de custo; as regulações nessa dimensão aparecem como fontes de rigidez, assim, a busca por flexibilidade é promovida como uma das condições básicas do crescimentoeconômico.

A abertura comercial e financeira brasileira responde, portanto, à emergência de um sistema financeiro mundial, passando a integrá-lo de forma "imperfeita" ou "incompleta", dentro de um todo de três peculiaridades, apontadas por Chesnais (1998) para os países em desenvolvimento. Em primeiro lugar, é fortemente hierarquizado: o sistema financeiro dos EUA domina os outros; em segundo lugar, esse todo "mundializado" é marcado por uma carência de instâncias de supervisão e controle; por fim, a unidade dos mercados financeiros é assegurada 
pelos operadores financeiros, em graus diferentes de um a outro compartimento. Destacando o primeiro aspecto, Cohen (2015) discute as motivações, as escolhas e as implicações presumidas a respeito da internacionalização que, impulsionada pela força da concorrência, produz uma hierarquia entre as moedas, alterando a geografia monetária a partir dos papéis que as nações estabelecem nos jogos financeiros e comerciais. A rivalidade para a participação de mercado, em regra, é a essência do processo de internacionalização.

O movimento conjunto de globalização e de financeirização colocou novos desafios para as estratégias nacionais dos países subdesenvolvidos, especialmente no que diz respeito à perda de autonomia nas definições de política econômica. O Brasil, foco de nossa análise, ao adotar as políticas recomendadas pelo discurso assumido a partir da financeirização, se colocou de forma regressiva na nova divisão internacional do trabalho, tendo que ajustar suas políticas fiscal, $\begin{array}{lllll}\text { monetária, cambial a } & \text { e } & \text { industrial as }\end{array}$ desígniosdafinançaglobal.Doisprincipaisatoresemergiramdesseprocesso:asempresas transnacionais, definindo os fluxos de produção, investimento e comércio, e os grandes bancos internacionais, controlando o mundo da finança. Essas regras acabaram diminuindo a competitividade das empresas nacionais, dificultando políticas industriais, tecnológicas e comerciais que fomentem a industrialização, além de tornar o manejo da taxa de câmbio e de juros restritos no que tange aos seus usos como instrumentos de desenvolvimento econômico e social (ANDRADE \& FERES,2018).

A compreensão das especificidades do atual padrão de acumulação exigem análises que possam explicitar os vínculos entre a acumulação de base rentista e patrimonial e o crescimento do estoque de capital fixo produtivo. Para elucidar esses vínculos, enquanto fatores fundamentais do crescimento e do desenvolvimento econômicos, diversas variáveis podem ser analisadas, uma vez que uma das hipóteses mais mobilizadas em análises desse tipo é a de que o baixo dinamismo da economia brasileira no período pós-liberalização decorre de fatores específicos do regime de acumulação que emergiu das transformações estruturais dos anos 1990. Bruno (2011) avalia esse fenômeno através do que ele denomina de "fatos estilizados da financeirização na economia brasileira", observando a evolução das taxas de lucro e de acumulação de capital fixo produtivo; a proporção do lucro macroeconômico alocada em ativos fixos; um indicador de financeirização ${ }^{1}$ e finalmente, a participação do estoque de capital fixo produtivo no estoque fixo total. Para testar a influencia da financeirização baseada na renda de juros o mesmo trabalho estima um modelo que se utiliza das seguintes variáveis explicativas: o nível de utilização da capacidade instalada, a taxa de lucro e um indicador sintético da razão

\footnotetext{
${ }^{1}$ Esse indicador é constituído pela razão entre o total de ativos financeiros não monetários, dado pela diferença entre os agregados monetários M4 e M1 (deflacionados pelo IGP-DI) e o estoque total de capital fixo produtivo líquido de depreciação, isto e, máquinas e equipamentos mais construções não residenciais. Essa relação expressa a arbitragem entre a alocação produtiva e sua alocaçãofinanceira.

\begin{tabular}{llllll}
\hline REVISTA ECONOMIA POLÍTICA DO DESENVOLVIMENTO & Maceió - AL & V.5 N.7. & JUNHO/2018 & P.68-79 & Página-76
\end{tabular}
}


entre o fator acumulado da taxa Selic real e o estoque de capital fixoprodutivo.

Estudos como de Bruno et al (2011) demonstram as peculiaridades da economia brasileira frente aos períodos anteriores, em vista de que as imobilizações do capital são multiplicadas e sofisticadas a partir das inovações financeiras, de comunição e de informação. O tipo de crescimento evidenciado pelos autores, subordinado à acumulação rentistafinanceira, tem como característica a reconcentração funcional da renda em favor dos detentores de capital, sem necessariamente induzi-los a elevar o nível de investimento produtivo, fator básico da geração de emprego e de renda.

A vigência de um regime macroeconômico subordinado à acumulação financeira não implica, necessariamente, estagnação econômica, porém, o que as evidencias empíricas parecem revelar é a instabilidade do crescimento econômico, assim como a redução de suas taxas. Esse fato decorreria das próprias características de um regime de acumulação do tipo finance-led growth, pois estes costumam afetar com mais intensidade o perfil de distribuição de renda, com grandes efeitos no mercado interno e, são mais sensíveis também às mudanças no cenário internacional.

Além do exposto, com parte expressiva das grandes empresas produtivas tendo sua estrutura de ativos comprometida com as operações financeiras, as alterações das expectativas empresariais se tornam cada vez mais curto prazistas, quanto mais alargado for o impacto das finanças sobre a forma de governança das empresas, do comportamento das famílias, da gestão do mercado de trabalho e da política, mais provável é que esse regime se apresente com séries de instabilidades estruturais. Outras evidências sugerem que o atual regime de acumulação, tem sido desfavorável aos salários e ao emprego, mas favorável aos lucros, entretanto esses lucros não impulsionam a taxa de acumulação de capital e, consequentemente, o crescimento econômico.

\section{CONSIDERAÇÕESFINAIS}

A teoria econômica mainstream concentra-se nas questões relacionadas ao mercado como o principal coordenador econômico entre agentes considerados iguais. Todavia, na medida em que se apreende a economia enquanto sistema complexo, no qual os mecanismos de desestabilização e conflito estão presentes tanto quanto os elementos de sua viabilidade, ficam escanteados pressupostos básicos desse arcabouço. Dessa forma, procuramos apresentar os conceitos básicos da teoria da regulação, objetivando respostas que não ignorem o caráter dinâmico do processo de acumulação e que pressupõe atores e estratégias para além de uma "economia pura".

Com isso, trouxemos a ideia de que a economia é uma organização social criada, ou por meio de legislação, ou por um processo evolucionário de invenção e inovação. A política pode mudar tanto os detalhes como o caráter geral da economia e o formato da política econômica envolvem não somente a definição de objetivos como também de um entendimento de que os 
processos econômicos atuais dependem das instituições econômicas e sociais (MINSKY,1986).

Aqueles que se alinham a essa perspectiva, de que cada economia e sociedade desenvolvem configurações particulares e que respondem pelos padrões de desenvolvimento, trazem a financeirização como uma transformação estrutural do capitalismo, não sendo apenas uma alocação neutra de capital, mas sim uma expressão de classe, um mecanismo de controle e uma racionalidade associada ao capitalismo contemporâneo, no qual o Estado tem papel essencial.

No caso brasileiro, algumas hipóteses podem ser elaboradas nesse sentido, ao analisar o padrão de ganhos pós década de 90 e apoiando-se no conceito de financeirização. A primeira hipótese é de que após 1994, com estabilização monetária e maior abertura financeira, modificase (ou aprofunda-se uma tendência de modificação de) o regime de acumulação; as características do regime de acumulação pós Plano Real prevalecem até 2004, quando tem início uma tentativa de mudança de padrão no processo acumulativo; por fim, o modo de regulação também prosseguiu em mudança, no sentido da redução do papel produtivo e planejador do Estado (com tentativas, fracassadas, de inflexão a partir de 2006), porém mantendo-se a centralidade da estabilidade monetária nas diretrizes da política econômica.

Outras tantas hipóteses podem ser desenvolvidas a partir desse arcabouço, porém as respostas ultrapassam em muito o escopo desse trabalho, que se apreende enquanto apontamento geral. Trabalhos no sentido de estabelecer as características gerais do regime de acumulação e do modo de regulação na economia brasileira devem ser desenvolvidos, buscando investigá-los e destacando suas mudanças ao longo do mesmo e frente ao período anterior. Assim, enquanto as formas institucionais dão o arcabouço necessário para a análise do modo de regulação, como uma combinação dos mecanismos que efetuam o ajuste dos comportamentos conflituosos dos indivíduos aos princípios coletivos do regime de acumulação, o próprio regime deve ser analisado como referente à lógica e às leis macroeconômicas que descrevem evoluções conjuntas das condições da produção, tais como a produtividade do trabalho, grau de mecanização e importância relativa dos diferentes ramos, bem como das condições de uso social dessa produção, sendo analisadas através dos dados de consumo familiar, investimentos, despesas governamentais e comércio exterior (LIPIETZ,1991).

De forma preliminar, o que podemos concluir é que dentro das condições de regime de acumulação financeirizado, o qual o Brasil se insere atualmente, taxas de expansão prolongadas ficam obstaculizadas, podendo ser significativos os impactos sociais e econômicos dessa forma de regime.

\section{REFERÊNCIAS BIBLIOGRÁFICAS}

AGLIETTA, M. Regulacion y crisis del capitalismo: la experiencia de los Estados Unidos. Madrid: Siglo XXI de Espana, 1979. 
ANDRADE, L. B; FERES, L. P. "Financeirização e os Sentidos do Desenvolvimento: Aspectos Teóricos e as Reformas de Mercado no Caso Brasileiro". In: Encontro Nacional de Economia Política, 2018, Rio de Janeiro. Anais eletrônicos. Rio de Janeiro, 2018.

BIS. Economic resilience: a financial perspective. Basle: Bank for International Settlements, 2016.

BOYER, R. "Is a finance-led growth regime a viable alternative to Fordism? A preliminary analysis". Economy and Society. Volume 29 number 1 february, 2000.

BOYER, R. Teoria da Regulação: os fundamentos. São Paulo: Estação Liberdade, 2009.

BRAGA, J. C. S. "Temporalidade da riqueza: teoria da dinâmica e financeirização do capitalismo". Tese de Doutoramento. Instituto de Economia da Unicamp, São Paulo 1985.

BRUNO, M. "Crescimento econômico, mudanças estruturais e distribuição: as transformações do regime de acumulação no Brasil". Rio de Janeiro, 2004. Tese de Doutorado - Instituto de Economia, Universidade Federal do Rio de Janeiro.

BRUNO, M. Macroanálise, regulação e o método: uma alternativa ao holismo e ao individualismo metodológicos para uma macroeconomia histórica e institucionalista. Revista de Economia Política, São Paulo, v. 25, n. 4, p. 337-356, 2005.

BRUNO, M. Acumulação de Capital, Distribuição e Crescimento Econômico no Brasil: Uma Análise dos Determinantes de Longo Prazo. Rio de Janeiro: Ipea, 2008. (Texto para discussão, n. 1364).

BRUNO, M.; DIWARA, H.; ARAÚJO, E.; REIS, A.N.; RUBENS, M. “Finance - Led

Growth Regime no Brasil: estatuto teórico, evidências empíricas e consequências macroeconômicas". In: Encontro Nacional de Economia Política, 2009, São Paulo. Anais eletrônicos. São Paulo, 2011.

CHESNAIS, F.(Coord.). A mundialização financeira: gênese, custos e riscos. São Paulo: Xamã, 1998.

CHESNAIS, F. "O capital portador de juros: acumulação, internacionalização, efeitos econômicos e políticos”. In: (Org.) Finança mundializada. São Paulo: Boitempo, 2005.

COHEN, B. J. “International Currency”. In: Currency Power: Understanding Monetary Rivalry. Oxford University Press, 2015.

COUTINHO, C. S. “A Escola da Regulação: Uma Revisão Crítica da Economia Política”. Nova Economia(UFMG.Impresso), Belo Horizonte, v. 1, n.1, p. 153-171, 1990.

EPSTEIN, G. A. "Introduction: Financialization and the World Economy”. In: Epstein,

G. A. Financialization and the World Economy.Edward ElgarPublishing, 2005.

FARIA, L. A. E. "As formas institucionais da estrutura: do micro ao macro na Teoria da Regulação". Ensaios FEE, Porto Alegre, v. ano 22, n.n. 1, p. 187-204, 2001.

HARVEY, D. A Condição pós-moderna: uma pesquisa sobre as origens da mudança cultural. 3. ed. São Paulo: Loyola, c1993.

KRIPPNER, G. “The Financialization of the American Economy”. Socio-Economic Review, 3, 173-208, 2005.

LAVINAS, L., ARAÚJO, E., BRUNO, M. "Brasil: vanguarda da financeirização entre os emergentes? Uma análise exploratória”. Texto para discussão, n.032. Rio de Janeiro: UFRJ, 2017.

LIPIETZ, A. Audácia: Uma alternativa para o século 21. Editora Nobel, São Paulo, 1991.

MINSKY, H. P. Stabilizing an Unstable Economy. Yale University Press, 1986.

PAULANI, L. M. "A crise do regime de acumulação com dominância da valorização financeira e a situação do Brasil”. Estudos Avançados, 23 (66) 2009.

PAULANI, L. M. “A inserção da economia brasileira no cenário mundial: uma reflexão sobre a situação atual à luz da história”. Boletim de Economia e Política Internacional, v. 10, p. 89-102,2012.

SERRANO, F. "Relações de poder e política macroeconômica americana, de Bretton Woods ao padrão dólar flexível”. In: FIORI, José Luis (org.). O poder americano. Petrópolis, RJ: Vozes, 2004.

UNCTAD.Trade and Development Report, 2016.

VAN DER ZWAN, N. “Making sense of financialization”. Socio-Economic Review, v. 12, 2014. 